\section{Pollination Study of Mandarins and the Effect on Seediness and Fruit Size: Implications for Seedless Mandarin Production}

\author{
Chih-Cheng T. Chao \\ Department of Botany and Plant Sciences, University of California-Riverside, \\ Riverside, CA 92521-0124
}

Additional index words. cross-pollination, flowering, open pollination, parthenocarpy, selfing, triploid

\begin{abstract}
A pollination study was conducted using 'Nules', 'Fina Sodea', 'Marisol', 'Fina' Clementine, 'Afourer', 'Tahoe Gold', and 'Gold Nugget' mandarin. The fruit sets from selfing of 'Fina', 'Marisol', 'Fina Sodea', 'Nules' Clementines and 'Afourer' mandarin were very low or near 0 . The open pollinated Clementines had very low fruit set and there were very few seeds per fruit. Fruit set was highest $(20 \%$ to $40 \%)$ in cross-pollination between two Clementines, 'Nules' and 'Fina Sodea', and 'Afourer' mandarin and their reciprocal crosses. There were averaged 23 to 32 seeds per fruit in Clementines $\times$ 'Afourer' mandarin crosses and averaged 5 to 12 seeds per fruit in 'Afourer' mandarin $\times$ Clementines crosses. Compatibility among Clementine mandarins and 'Afourer' mandarin is very high and caution should be taken to properly isolate these two types of mandarins when planting to produce seedless fruit. The diploid 'Nules' Clementine $\times$ triploid 'Tahoe Gold' mandarin gave $14 \%$ and $17 \%$ fruit sets in 2002 and 2003, with an average 2 seeds and 9 seeds per fruit in 2002 and 2003, respectively. Caution should also be taken when planting triploid seedless 'Tahoe Gold' mandarin near diploid 'Nules' Clementine to avoid seeds. The compatibilities and seediness between diploid mandarin cultivars and new seedless triploid mandarin cultivars need to be tested to ensure the pollen of the new triploid cultivars will not cause seeds in the existing diploid cultivars.
\end{abstract}

The planting of mandarins in California has increased dramatically in the past 10 years as the market preference has changed to easypeeling seedless mandarins. The increased importation of Clementine mandarin (Citrus clementina Hort. Ex Tan.) from Spain, Morocco and other countries also encourages California citrus growers to plant new mandarins. Large plantings of two types of mandarins have been common in recent years. The first type is the Clementine mandarin originating from Spain or Morocco. Currently there are 16 Clementine cultivars in California. 'Nules' (also called 'Clemenules' or 'De Nules') (Saunt, 2000) has the highest planting in California. Other Clementine cultivars such as 'Caffin', 'Fina Sodea' and 'Sidi Aissa' also are grown in limited planting. The second type of mandarin increasing in popularity in California is the 'Afourer'mandarin (also called 'W. Murcott' or sold under the trade name Delite). Clementine

Received for publication 27 Apr. 2004. Accepted for publication 30 Aug. 2004. I acknowledge the funding support from the California Citrus Research Board, 5100-123. I thank J.S. Semancik and the late D.J. Gumpf, Citrus Clonal Protection Program, Department of Plant Pathology, University of CaliforniaRiverside for providing the Clementine block and L. Ferguson, Department of Pomology, University of California-Davis for providing the 'Afourer' block for the study. I thank P.S. Devanand, J. Dotty, and C. Ratnayake for their technical assistance, J.J. Chen and J. Fang for the critical reading of the manuscript.

${ }^{1}$ Assistant cooperative extension specialist and assistant horticulturist; e-mail ctchao@citrus.ucr.edu. mandarins are early to midseason mandarins that mature from October to January depending on the cultivar, location, and environment. 'Afourer' mandarin is a late season mandarin that matures from late January to April depending on location and environment. Both types of mandarins have good rind color and are easy peeling, great tasting, and almost completely seedless if grown in isolation. However, both groups of mandarins can be very seedy if there are compatible pollen sources nearby. Valencia orange (C. sinensis L. Osbeck), grapefruit ( $C$. paradisi Macf.), and some mandarin hybrids could be excellent pollen sources for seed production in Clementine mandarins and 'Afourer' mandarin based on their pollen germination rate (Barry, 1995). Clementine mandarins have a self-incompatibility system that prevents selfing and results in seedless fruit if they are grown in isolation (Soost, 1965). It is known from experience in California that Clementine mandarins and 'Afourer' mandarin are also compatible with each other and seeds can be produced if they are planted in close proximity. However, it is unknown how seedy these two groups of mandarins could be if planted together. A third type of mandarins recently released by the citrus breeding program at University of California-Riverside are the seedless 'Gold Nugget' mandarin (Roose et al., 1999) and seedless triploid 'Tahoe Gold' mandarin (Roose, personal communication). These two mandarin cultivars are completely seedless even in mixed plantings. However, whether the pollen of these mandarins can cause seeds in diploid mandarins like Clementine or 'Afourer' mandarin is unclear. I initiated a pollination study among these three groups of mandarins in 2002 and 2003 to answer these questions. The results from this study have very important implications for seedless mandarin production in California and elsewhere.

\section{Materials and Methods}

The experiment was conducted at the University of California (UC) Lindcove Research and Extension Center (LREC) near Exeter, Calif. The Clementine mandarins used in the study belonged to the Clementine mandarin cultivar trial established by the late David Gumpf, Citrus Clonal Protection Program (CCPP), Department of Plant Pathology, UCRiverside. The 'Afourer' mandarin that used in the study belonged to a trial established by Louise Ferguson, Department of Pomology, UC-Davis. The 'Gold Nugget' and 'Tahoe Gold' mandarins used in the study are part of the CCPP foundation block at LREC. For selfing, unopened flowers near blooming were covered with cotton bags, tagged, and recorded. For open pollination, opened flowers were covered with cotton bags, tagged, and recorded. For parthenocarpy treatment, unopened flowers were emasculated, covered with cotton bags, tagged and recorded. About 100 flowers of 'Fina', 'Marisol', and 'Fina Sodea' were used for each type of treatment in 2002; 'Nules' and 'Afourer' were added for 2003 (Table 1). Unopened flowers near blooming were selected and emasculated for the hand cross-pollination study. Flowers of recently opened male parents were collected, stamen with pollen shedding appearance were directly applied to the stigma of the emasculated flowers of the female parents. The cross pollinated flowers were then covered, tagged and recorded. Any opened or unopened flowers on the same branch not used in hand cross-pollination were removed before the bagging. Cotton bags were removed about one month after the pollination. Fruit of Clementine mandarins were harvested in late November each year and fruit from 'Afourer' mandarin were harvested in late January the following year. All fruit were counted, and diameter and weight were measured. Seeds from each fruit were counted. The relationship between fruit size and seed number per fruit was analyzed by regression analysis (SigmaPlot, SPSS Inc., Chicago, Ill.).

\section{Results}

Relationship between seed number and fruit size. The diameter and weight of all fruit from all different types of crosses were recorded. In general there were positive correlations between the seed number per fruit and the size and weight of the fruit. There is a positive relationship between fruit size $(\mathrm{mm})$ and seed number per fruit $(R=0.59)$ as shown in Fig. 1. The linear correlation between fruit size $(\mathrm{y})$ and seed number per fruit $(\mathrm{x})$ is $\mathrm{y}=54.62+$ $0.464(\mathrm{x})$. Fruit with larger number of seeds have large fruit size and fruit weight. The average diameter for fruit with $\leq 5$ seeds per 
Table 1. Results of selfing, open-pollination (OP), and parthenocarpy (Parth), in cross-pollination studies of mandarins in 2002 and 2003.

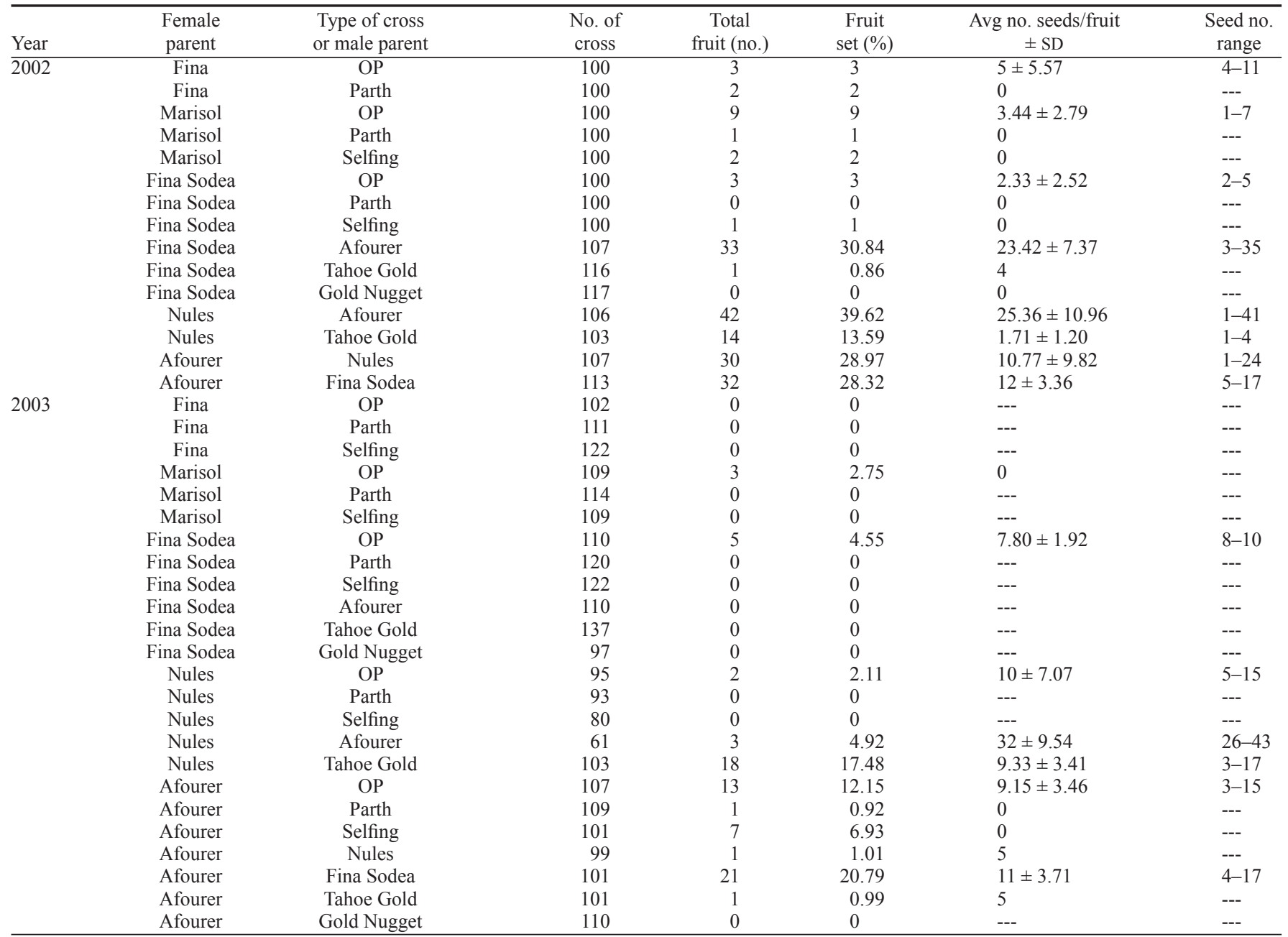

fruit was $55.47 \mathrm{~mm}$ and the average diameter for fruit with $\geq 36$ seeds per fruit was $74 \mathrm{~mm}$ (data not shown).

Fruit set and seed number. The fruit set percentage, average seed number, and seed number ranges from the 2002 and 2003 pollination results are shown in Table 1. The 2002 season had relatively normal weather when we conducted the experiment. There was adequate chilling in the winter season before the bloom and no excessive heat weave during or after the bloom. However, Winter 2002-03 was abnormally warm in California, the chilling hour accumulation was low and the flowering of some Clementine mandarins might be affected by the lack of chilling. The chilling hour accumulation in Winter 2002-03 at LREC was $810 \mathrm{~h}$ as of 28 Feb. 2003 compared to $1,232 \mathrm{~h}$ and $974 \mathrm{~h}$ for Winter 2000-01 and 2001-02 at end ofFebruary, respectively. The bloom of 'Nules' Clementine was prolonged into late May and there were a lot of terminal leafy-inflorescences. Normally, most mandarin cultivars finish blooming in April. Theflowering of 'Fina Sodea'Clementine was not affected by the lack of chilling. The percentage of parthenocarpy and selfing was very low among all Clementine mandarins. Selfing of 'Marisol' ranged from $0 \%$ in 2003 to a maximum $2 \%$ in 2002 . None of the fruit had any seed. The fruit set percentage from open pollinated fruit of Clementine mandarins ranged from $0 \%$ for 'Fina' in 2003 to $9 \%$ for 'Marisol' in 2002. Most of the open pollinated fruit had seeds ranging from 0 to an average of 7.80 seeds per fruit for 'Fina Sodea' in 2003.

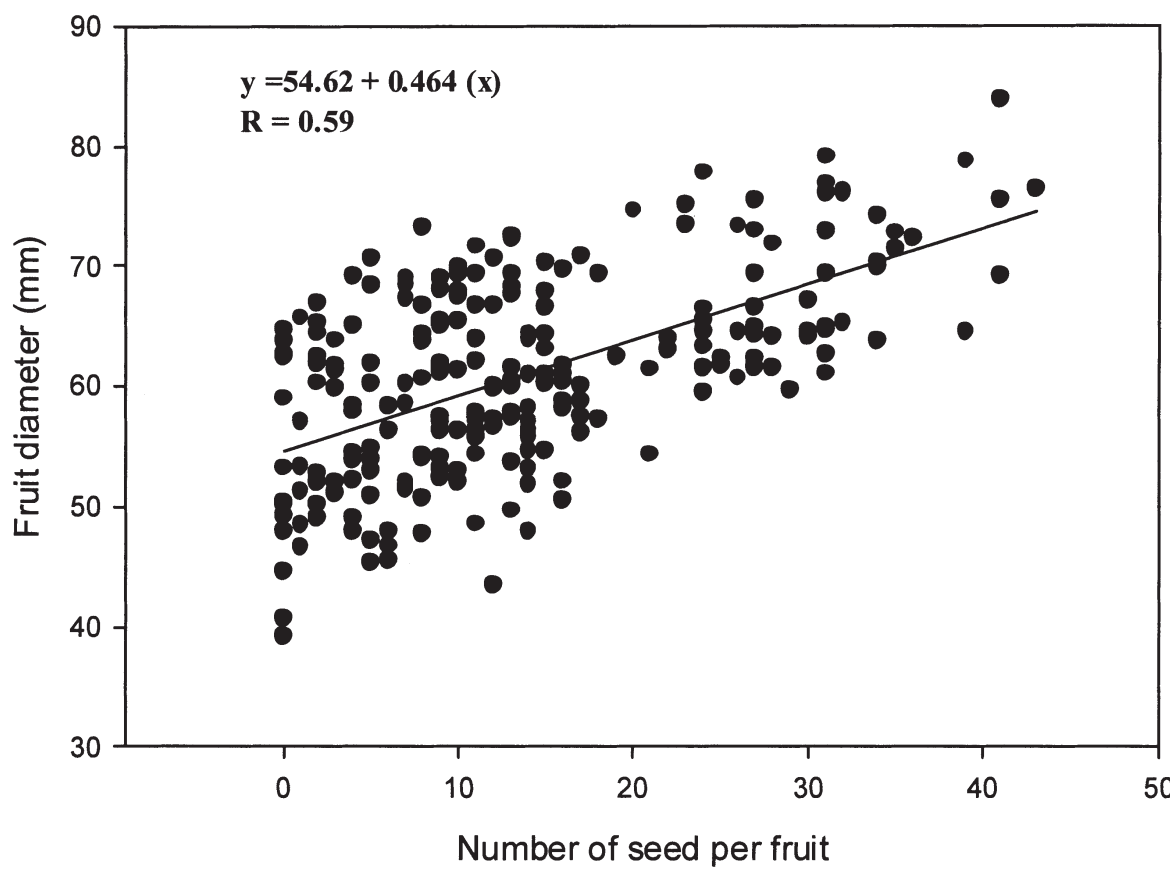

Fig. 1. Relationship between fruit size $(\mathrm{mm})$ and number of seed per fruit; $\mathrm{y}=54.62+0.464(\mathrm{x}), R=0.59$
These results show the natural fruit set rate for Clementine mandarins in a mixed planting was low, even though there were compatible pollen sources available. 
For 'Fina Sodea' Clementine mandarin, the crosses with 'Tahoe Gold' mandarin gave $0.86 \%$ fruit set in 2002 and $0 \%$ in 2003 . There was no fruit set from crosses between 'Fina Sodea' Clementine and 'Gold Nugget' mandarin in either year. There was $30.84 \%$ fruit set $(33 / 107)$ from crosses between 'Fina Sodea' Clementine and 'Afourer' mandarin in 2002 and $0 \%$ fruit set in 2003. An average of 23.42 seeds per fruit was found from the 2002 crosses. The crosses between 'Nules' Clementine and 'Tahoe Gold' mandarin gave $13.59 \%$ fruit set $(14 / 103)$ in 2002 and $17.48 \%$ fruit set $(18 / 103)$ in 2003. For 2002, there was an average of 1.71 seeds per fruit and an average of 9.33 seeds per fruit in 2003. A very high fruit set rate, $39.62 \%(42 / 106)$ was found between crosses of 'Nules' Clementine $\times$ 'Afourer' mandarin in 2002 and a low fruit set of $4.92 \%(3 / 61)$ occurred in 2003. In both years, despite the difference in fruit set \%, there was an average of 25.36 seeds per fruit in 2002 and an average of 32 seeds per fruit in 2003. There was $28.97 \%$ fruit set and $28.32 \%$ fruit set for 'Afourer' mandarin $\times$ 'Nules' Clementine and 'Afourer'mandarin $\times$ 'Fina Sodea' Clementine in 2002, respectively. The 'Afourer' mandarin $\times$ 'Nules' Clementine had an average of 10.77 seeds per fruit and the 'Afourer' mandarin $\times$ 'Fina Sodea' had an average of 12 seeds per fruit. In 2003, the fruit set was $1.01 \%$ (1/99) and 20.79\% (21/101) for 'Afourer' mandarin $\times$ 'Nules' clementine and 'Afourer' mandarin $\times$ 'Fina Sodea' Clementine crosses, respectively. The fruit from 'Afourer' $\times$ 'Fina Sodea' cross had an average of 11 seeds per fruit. The crosses between 'Afourer' mandarin and the two seedless mandarins, 'Tahoe Gold' and 'Gold Nugget', had near 0 or 0 fruit set. 'Afourer' mandarin had low selfing (6.93\%) and parthenocarpy $(0.92 \%)$ rates. The open pollinated flowers of the 'Afourer' mandarin had $12.15 \%$ fruit set $(13 / 107)$ with an average of 9.15 seeds per fruit.

\section{Discussion}

Relationship between fruit size, fruit weight and seed number. Cross-pollination can significantly increase the fruit set (yield), number of seed per fruit, or fruit size in many crops like avocado (Persea americana Mill.) (Degani et al., 1990), southern highbush blueberry (Vaccinium corymbosum L.) (Lang and Danka, 1991), and lychee (Litchi chinensis Sonn.) (Stern et al., 1993); as well as in many citrus such as Clementine mandarin (Soost, 1956), 'Orlando' tangelo (Moffett and Rodney, 1973), 'Star Ruby' grapefruit (Burger, 1985), 'Ellendale' tangor (Vithanage, 1991), and 'Murcott', 'Imperial', and 'Ellenor' mandarins (Wallace and Lee, 1999). In the current study, we found a similar positive relationship between seed number per fruit versus fruit diameter (Fig. 1) and between seed number per fruit versus fruit weight. Seedless fruit, which is demanded by the market, are usually smaller in size and weight, but the price can be lower if fruit size is too small. In California and other mandarin producing countries, plant growth regulators such as 3,5,6-trichloro-2-pyridyloxyacetic acid, 2,4-dichlorophenoxypropionic acid, or 2,4-dichlorophenoxy acetic acid are used to enhance fruit size of seedless mandarins and mandarin hybrids (El-Otmani et al., 2000).

Fruit set and seed number from diploid mandarin $\times$ triploid mandarin crosses. The hand cross-pollination results from the crosses involving 'Tahoe Gold' mandarin as pollen parents were very intriguing. 'Tahoe Gold' mandarin is a triploid cultivar derived from crosses of [('Temple' $\times 4 n$ 'Dancy') $\times$ 'Encore'] and it is completely seedless even if grown in mixed plantings. It was unexpected to obtain any fruit $(13.59 \%$ fruit set) or seed (average 1.71.seeds per fruit) from the cross between 'Nules' Clementine $\times$ 'Tahoe Gold' mandarin in 2002. However, the repeated crosses made in 2003 also obtained a similar fruit set (17.48\%) and an even higher average of 9.33 seeds per fruit. There was extremely low fruit set $(0.86 \%)$ and no fruit set from the 'Fina Sodea' Clementine $\times$ 'Tahoe Gold' mandarin in 2002 and 2003, respectively. Why was there such a difference in fruit set percent between these two Clementine mandarins when they were crossed with 'Tahoe Gold' mandarin? One possible explanation is that there are some genetic differences in the incompatibility systems between these two Clementines; pollen of 'Tahoe Gold' mandarin was compatible with 'Nules' Clementine, but incompatible with 'Fina Sodea' Clementine. Self-incompatibility systems are known to exist in Clementine mandarins and other citrus (Soost, 1965). Both 'Nules', from Spain, and 'Fina Sodea', from Morocco, are bud mutations of 'Fina' Clementine. Genetically, Clementine mandarins are closely related and very difficult to be differentiated by molecular markers (Breto et al., 2001).

Another interesting question is how fruit was set and seed was derived from the cross between diploid 'Nules' Clementine and triploid 'Tahoe Gold' mandarin. The pollen germination rate of the triploid 'Tahoe Gold' is around $10 \%$ (Roose, personal communication), but the pollen is not expected to successfully fertilize diploid mandarin. One possible explanation is that the triploid 'Tahoe Gold' mandarin may be able to produce functional pollen grains and produce viable seeds with diploid 'Nules' Clementine. Natural triploid occurrence is somewhat uncommon in plants, but some triploids can produce low percentages of functional pollen when used as the male parent in crossing with a diploid or tetraploid female, for example in Datura stramonium L. (Satina and Blakeslee, 1937), Triticum monococcum L. (Kuspira et al., 1986) and pearl millet (Pennisetum glaucum L.) (Dujardin and Hanna, 1988), and can result in different aneuploid progenies such as in triploid corn (McClintock, 1929), or diploid or tetraploid progenies such as in triploid hyacinths (Hyacinthus orientalis L.) (Darlington, 1963). In citrus, a hybrid triploid male plant was crossed with four diploid female plants including a Clementine. These four crosses produced 188 diploids $(2 \mathrm{n}$ $=18)$, three haploids $(1 \mathrm{n}=9)$, three triploids $(3 n=27)$, one tetraploid $(4 n=36)$ and 28 aneuploids $(2 \mathrm{n}=19)$ (Oiyama and Kobayashi, 1993). Another possibility is that the pollen of
'Tahoe Gold' mandarin was able to stimulate the production of a nucellar embryo in diploid 'Nules' Clementine. To determine the possible mechanism responsible for the seed production, further investigation is underway using molecular markers to determine the parentage of the seeds and determine the ploidy levels of the seedlings.

Implication for seedless mandarin production. The results showed that large numbers of seed could be produced from Clementine mandarins $\times$ 'Afourer' mandarin or in the reciprocal cross of 'Afourer' mandarin $\times$ Clementine mandarins. This is the first data showing the "worst case scenario" of seeds, if Clementine mandarin is planted next to an 'Afourer' mandarin. Cross-pollination of 'Ellendale' tangor with 'Murcott' and 'Emperor' mandarin pollen gave higher fruit set and seeds per fruit. Pollen of 'Imperial' mandarin gave low seed numbers when crossed with 'Ellendale' tangor (Vithanage, 1991). These results showed that there are different levels of compatibility among different citrus and some combinations can give very high seed numbers. 'Imperial' mandarin was recommended to be inter-planted with 'Ellendale' tangor to increase fruit set without too much concern for increasing seed number. 'Orlando' tangelo has self-incompatibility (Krezdorn and Robinson, 1958), but it gave a $26 \%$ fruit set and an average of 22 seeds per fruit when used as the pollen source to cross with 'Robinson' mandarin (Reece and Register, 1961). In the hand cross-pollination study, a much larger amount of pollen was applied to the stigma than would occur naturally. The results demonstrated how many seeds could occur if these two types of mandarin were crossed. In a sampling of a commercial field near Bakersfield, Calif., that included plantings of 'Nules'Clementine and 'Afourer'mandarin, a maximum of 36 seeds per fruit was found in 'Nules' Clementine and a maximum of 16 seeds per fruit was found in 'Afourer' mandarin in 2002 (Chao, unpublished). When there are compatible pollen sources and pollinators, the maximum seed number per fruit from field sampling is similar to that of hand cross-pollination. Proper distance, possibly up to a few kilometers, is needed between these two types of mandarin to avoid cross-pollination by bees and to ensure seedless mandarin production. The cross between 'Afourer' mandarin and 'Nules'Clementine had near $0(1.01 \%)$ fruit set in 2003. The flowering of 'Nules' Clementine was severely prolonged in 2003 because the low chilling accumulation in the winter of 2002-03. It was very difficult to find open flowers as pollen sources for crossing with 'Afourer' mandarin in April 2003 and that might have contributed to the very low fruit set percent. In a typical weather season like 2001-02, the crosses between 'Afourer' mandarin and Clementines should produce reasonable fruit set with a high seed number.

'Afourer' mandarin has one of the most consistent fruit set patterns in California annually, based on observations throughout California in the past 3 years. It was not affected by the low chilling accumulation in the winter of 2002-03 and flowers of 'Afourer' bloomed normally. 
In isolation, 'Afourer' mandarin produces nearly seedless fruit. The parthenocarpy rate of 'Afourer' mandarin was near zero in 2003, but it had a $6.93 \%$ selfing rate in 2003 . The consistent fruit set of 'Afourer' mandarin may attribute to its selfing capability. Further investigation is underway.

'Gold Nugget' is another seedless mandarin in California Our results showed that pollen of 'Gold Nugget' mandarin would not produce any seed in Clementine or 'Afourer' mandarin. Pollen of 'Tahoe Gold' mandarin could produce seeds in 'Nules' Clementine, especially if temperatures were higher during the blooming period. Caution should be taken in planting these two mandarins together, due to the seediness. Pollen of 'Tahoe Gold' mandarin produced almost no seed in 'Fina Sodea' Clementine in 2002 and 2003 and in 'Afourer' mandarin in 2003. Most likely, 'Tahoe Gold' could be planted in proximity with 'Fina Sodea' Clementine and 'Afourer' mandarin without too much concern for seed.

The study showed that fruit with larger number of seed also have larger fruit size. In California, plantings of 'Afourer' mandarin sometimes could not be totally isolated from compatible pollen sources, producing some seeds in the fruit. Packinghouses are using fruit size as a criterion to grade the fruit. Larger fruit of 'Afourer' mandarin could be downgraded due to concerns for seeds and command a much lower price in the market.

\section{Literature Cited}

Barry, G.H. 1995.Aprediction model to determine the croo-pollination ability of Citrus spp. MS thesis. Univ. Natal, Pieteermaritzburg, Rep. S. Afr.

Breto, M.P., C. Ruiz, J.A. Pina, and M.J.Asins. 2001. The diversification of Citrus clementina Hort. Ex Tan., a vegetatively propagated crop species. Mol. Phyl. Evol. 21:285-293.

Burger, D.W. 1985. Pollination effects on fruit production of 'Star Ruby'grapefruit (Citrus paradisi Macf.). Scientia Hort. 25:71-76.

Darlington, C.D. 1963. Chromosome botany and the origins of cultivated plants. Allen \& Unwin Ltd., London.

Degani, C., A. Goldring, I. Adato, R. El-Batsri, and S. Gazit. 1990. Pollen parent effect on outcrossing rate, yield, and fruit characteristics of 'Fuerte' Avocado. HortScience 25:471-473.

Dujardin, M. and W.W. Hanna. 1988. Cytology and breeding behavior of a partially fertile triploid pearl millet. J. Hered. 79:216-218.

El-Otmani, M., C.W. Coggins, M. Agusti, and C.J. Lovatt. 2000. Plant growth regulators in citriculture: world current uses. Crit. Rev. Plant Sci. 19:395-447.

Krezdorn, A.H. and F.H. Robinson. 1958. Unfruitfulness in the Orlando tangelo. Proc. Fla. State Hort. Soc. 71:86-91.

Kuspira, J., R.N. Bhambhani, R.S. Sadasivaiah, and D. Hayden. 1986. Genetic and cytogenetic analyses of the A genome of Triticum monococcum. III. Cytology, breeding behavior, fertility, and morphology of autotriploids. Can. J. Genet. Cytol. 28:867-887.

Lang, G.A. and R.G. Danka. 1991. Honey-bee-mediated cross versus self-pollination of 'Sharpblue' blueberry increase fruit size and hastens ripening. J. Amer. Soc. Hort. Sci. 116:770-773.

McClintock, B. 1929. A cytological and genetical study of triploid maize. Genetics 14:180-222.

Moffett, J.O. and D.R. Rodney. 1973. Honey bee visits increase yields of 'Orlando' tangelo. HortScience 8:100.

Oiyama, L.I. and S. Kobayashi. 1993. Haploids obtained from diploid $\times$ triploid crosses of citrus. J. Jpn. Soc. Hort. Sci. 62:89-93.

Reece, P.C. and R.O. Register. 1961. Influence of pollinators on fruit set on Robinson and Osceola tangerine hybrids. Proc. Fla. State Hort. Soc. 74:104-106.

Roose, M.L., T.E. Williams, J.W. Cameron, and R.K. Soost. 1999. 'Gold Nugget' mandarin, a seedless, late-maturing hybrid. HortScience 35:1176-1178.

Satina, S. and A.F. Blakeslee. 1937. Chromosome behavior in triploids of Datura stramonium. I. The male gemetophyte. Amer. J. Bot. 24:518-527.

Saunt, J. 2000. Citrus varieties of the world, an illustrated guide. Sinclair Intl., Norwich, England.

Soost, R.K. 1956. Unfruitfulness in the Clementine mandarin. Proc. Amer. Soc. Hort. Sci. 84:171-175.

Soost, R.K. 1965. Incompatibility alleles in the genus Citrus. Proc. Amer. Soc. Hort. Sci. 87:176-180.

Stern, R.A., S. Gazit, R. El-Batsri, and C. Degani. 1993. Pollen parent effect on outcrossing rate, yield, and fruit characteristics of 'Floridian' and 'Mauritius' lychee. J. Amer. Soc. Hort. Sci. 118:109-114.

Vithanage, V. 1991. Effect of different pollen parents on seediness and quality of 'Ellendale' tangor. Scientia Hort. 48:253-260.

Wallace, H.M., B.J. King, and L.S. Lee. 2002. Pollen flow and the effect on fruit size in an 'Imperial' mandarin orchard. HortScience 37:84-86.

Wallace, H.M. and L.S. Lee. 1999. Pollen source, fruit set and xenia in mandarins. J. Hort. Sci. Biotechnol. 74:82-86. 